However, in order to diminish her spasticity she continued at her home treatment of mobilisation by a physiotherapist. During one of the treatments, the right femur was fractured, causing a transverse fracture. She was immediately brought back to the centre and we operated by inserting a pin. This was not successful owing to osteoporosis of the bone. Even with a bone graft it was not possible to obtain callus and the spasticity did not allow immobilisation of the fracture. At this phase, an intra-thecal alcoholisation may have been the solution but the patient refused, and considering the height of the lesion, we did not insist, as the possibility to learn to walk was very limited and the continuation of the automatic bladder was important.

Following this paper a considerable number of X-rays were shown of fractures in individual patients and their management and follow-up.

\title{
CONCLUSIONS
}

Associated fractures with paraplegia are relatively frequent. The number seems to be increasing. Their importance is essential, especially when there is an aggravation of the disability.

These fractures must be treated as early as possible. For nearly all the fractures of the limbs, an osteosynthesis is necessary. If the osteosynthesis is correctly made there are no problems for a good consolidation of the fracture. The rate of healing has been in no case longer than normal and sometimes seems to be even shorter. This seems paradoxical considering the osteoporosis which appears in the majority of the cases and also the absence of muscle action of the paralysed limbs which is considered to be essential for the healing of limb fractures.

\section{ASSOCIATED INJURIES IN TRAUMATIC PARAPLEGIA AND TETRAPLEGIA}

\author{
By Phillip Harris, F.R.C.S.E. F.R.C.P.E., F.R.C.S.(Glas.), F.R.S.Ed. \\ Department of Surgical Neurology, Western General Hospital, \\ Edinburgh, Scotland
}

IN civilian life and in war, the effects of an accident are not necessarily confined to one region or system of the body. Indeed about a third of all patients requiring admission to hospital as a result of an accident, have a significant associated injury. Complex clinical syndromes often ensue in these patients, and one condition may greatly influence another (London, 1964). Accidents occurring at high speeds and in particular road traffic accidents, are quite likely to result in multiple injuries and if serious spinal trauma occurs it is commonly associated with another significant injury (Tables I and II). Falls from a height may result in more than one serious injury, and it is easily understood that penetrating wounds of the spine very commonly involve associated parts of the body. A good maxim is that anyone suffering from a head injury should also be considered to have a cervical spinal injury until proved otherwise by proper clinical and radiological examination. 
TABLE I

Spinal Injury and Associated Injury

\begin{tabular}{|c|c|c|c|c|}
\hline & Cervical & Dorsal & Lumbar & Total \\
\hline Patients with Spinal Injury. & 67 & 60 & 23 & 150 \\
\hline Associated injury- & & & & \\
\hline $\begin{array}{l}\text { Minor. } \\
\text { Major . }\end{array}$ & $\begin{array}{l}25 \\
13\end{array}$ & $\begin{array}{l}22 \\
17\end{array}$ & $\begin{array}{l}8 \\
6\end{array}$ & $\begin{array}{l}55 \\
36\end{array}$ \\
\hline Total . & 38 & 39 & I4 & $9 \mathrm{I}$ \\
\hline Two major injuries & 5 & 4 & 3 & 12 \\
\hline Three major injuries & 0 & I & 0 & I \\
\hline Four major injuries & o & I & o & I \\
\hline
\end{tabular}

TABLE II

Site of Associated Injuries

\begin{tabular}{|c|c|c|c|c|}
\hline & Cervical & Dorsal & Lumbar & Total \\
\hline Head-Minor $\star$ & I8 & 8 & 4 & 30 \\
\hline Major & 12 & 6 & 2 & 20 \\
\hline Chest-Minort & I & 8 & I & IO \\
\hline Major & 2 & 6 & 2 & IO \\
\hline Compound fracture mandible & - & 6 & - & 2 \\
\hline Atlanto-axial fract. dislocation & - & - & I & I \\
\hline Brachial plexus . & I & - & - & I \\
\hline Dislocation shoulder joint & - & I & - & I \\
\hline Fracture humerus . & - & I & - & I \\
\hline Severe hand injury & I & I & - & 2 \\
\hline Severe fracture pelvis & I & - & I & 2 \\
\hline Rupture liver & - & I & - & I \\
\hline Dislocation hip joint & - & I & - & I \\
\hline Fracture femur & I & I & - & 2 \\
\hline Fracture tibia and fibula & - & 2 & I & 3 \\
\hline Severe soft tissue: shock & 2 & 3 & I & 6 \\
\hline Multiple G.S.W. . & I & $\underline{-}$ & - & I \\
\hline Fracture maxilla ${ }^{\star}$ & - & I & - & I \\
\hline Acromio-clavicular dislocation & - & I & - & I \\
\hline Fracture scapula ${ }^{\star}$ & I & - & - & I \\
\hline Colles fracture ${ }^{\star}$ & 4 & 3 & 2 & 9 \\
\hline Fracture calcaneus ${ }^{\star}$ & - & I & 3 & 4 \\
\hline Horner's syndrome ${ }^{\star}$ & 2 & - & $\underline{-}$ & 2 \\
\hline Severe lacerations` ${ }^{\star}$ & 5 & 2 & - & 7 \\
\hline
\end{tabular}

$\star=$ A minor associated injury.

$\dagger=$ Unconscious for minutes only and amnesia less than 12 hours. 
Intubation of a patient following an accident to ensure a clear airway, or to administer an anaesthetic, must be done with extra care because the hyperextension of the neck necessary for this procedure may seriously compromise the cervical spinal cord in someone with an unsuspected or even a diagnosed neck injury, or in a person with cervical spondylosis.

\section{DIAGNOSIS}

A person who has had an injury requires to be carefully and fully examined and the possibility of multiple injuries must be considered. Damage to the cervical spinal cord may cause severe hypotension, and on the other hand, oligaemic shock can arise from an associated injury such as serious external trauma where there has been considerable blood loss, or from internal haemorrhage from trauma to the abdomen or chest, or from a fractured femur or pelvis. Injury to the feet, resulting from a fall; or to the head or face, should raise the possibility of an associated spinal injury. It must be appreciated that a person who has been involved in an accident may not show early evidence of injury to more than one part of the body and therefore close observation and repeated examinations are necessary. In addition to clinical examination, echo encephalography can be very helpful in the diagnosis of acute intracranial haematoma. In a patient who is unconscious from a head injury, a co-existing severe spinal injury can be diagnosed because of such signs as flaccidity of paralysed limbs, and these will not respond to noxious stimulation. The deep reflexes may be absent and the plantar reflexes absent or flexor, instead of being extensor as may be expected after a head injury. Noxious stimulation may demonstrate an upper sensory level, and if the injury is in the cervical region intercostal respiration may be absent, and the blood pressure may be abnormally low. Sweating may be absent below the level of the spinal lesion, priapism often occurs. Deformity of the spine and skin bruising or ecchymosis may be seen.

\section{SITES AND FREQUENCY OF ASSOCIATED INJURIES}

No part of the body is immune when an accident has occurred. Guttmann (1963), discussing 396 patients with traumatic paraplegia or tetraplegia, who were admitted within I5 days of the accident to his spinal injury centre, reported that II 3 had an associated injury ( 28 per cent.). These included fractures of the skull, with or without cerebral concussion, fractures of long bones, fractured ribs resulting in pneumothorax or pneumo-haemothorax, fractured sternum, and injuries to internal organs. In his series, death from head injury occurred in seven patients and from multiple injuries in three. Harris (1966) found that 43 of II4 patients with cervical spinal cord injury had an associated injury, including $3 \mathrm{I}$ to the head or facio-maxillary region (fig. I), eight with a serious limb fracture, two with thoracic trauma, and one patient had a serious fracture of the pelvis. Penetrating injuries of the spinal cord have been well described by Berry, Meirowsky, Wannamaker, Barnett and Clark (Meirowsky, 1965). In a large series of patients injured during the Korean War they describe in some detail, and give statistics for, spinal cord and associated injuries, these latter included intra-thoracic haemorrhage, intestinal perforations, intra-abdominal haemorrhage, peripheral nerve injuries, head injury, fracture mandible and 
fracture limb bones; thus, in the section on thoracic spinal wounds, 65 per cent. of casualties had a major associated injury (Barnett, J. C., Jr.). Stab wounds of the spinal cord are described by Lipschitz and Block (I962), in a study of I30 patients. The wounds were usually multiple and often involved different parts of the body, including thoracic and abdominal viscera, major blood vessels such

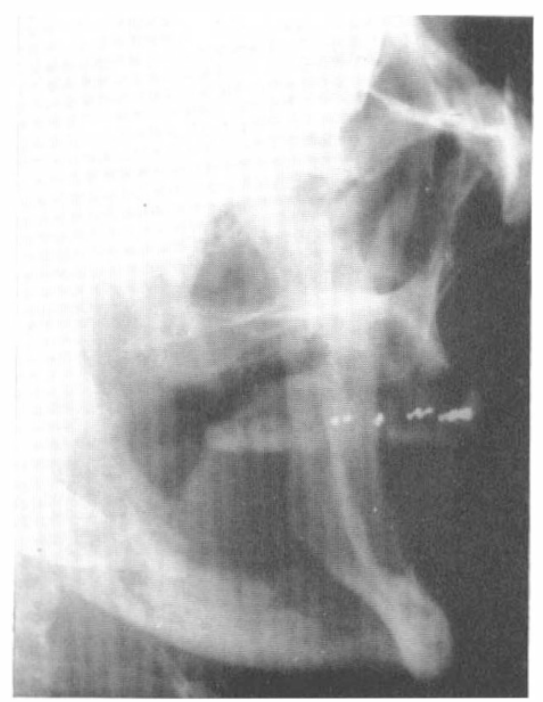

FIG. I

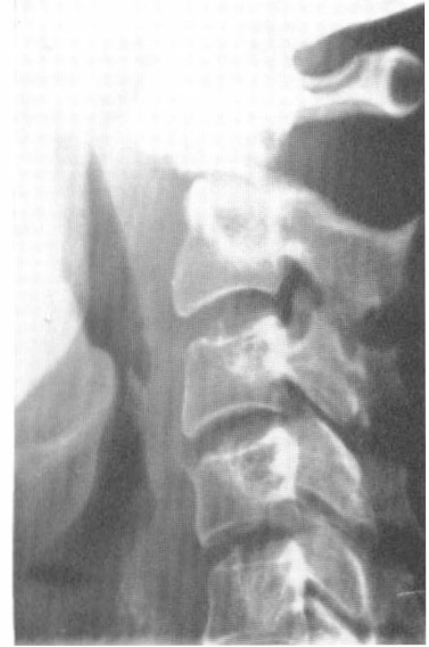

FIG. 2

Figure I-Radiograph showing compound fracture of mandible.

Figure 2-Radiograph of a patient who sustained a serious fracture dislocation of LI, 2 and 3 vertebrae, and the associated injuries of bilateral calcaneal fractures, Colles fracture, and (as shown in fig.) an atlantoaxial fracture dislocation.

as those in the neck; and the brachial plexus. The brachial plexus may also be involved with a closed cervical spinal injury and this can present difficulties in diagnosis unless the possibility of the combined lesions is considered. Dislocation of the shoulder or a fracture or dislocation of the clavicle may be found in these patients, and the mechanism is often one of severe lateral flexion of the head and neck and downward displacement of the ipsi-lateral shoulder. Sudden severe hypertension or lateral rotation and flexion of the neck may cause damage to one or both vertebral arteries in the neck (Schneider, I96I), and this possibility must always be considered in injuries to the cervical spine, especially if there is also evidence of brain stem involvement.

Some of the features of a study of I50 unselected patients admitted directly to the Department of Surgical Neurology in Edinburgh, or to the Spinal Unit, Edenhall Hospital, Musselburgh, are set out in Tables I and II. In Table I it is noted that 36 patients had a serious associated injury, and another 55 had one or more minor lesions. Twelve patients sustained two major injuries in addition to the severe spinal injury. Table II shows the sites of these lesions, head injury 
being commonest in cervical, and chest injury in dorsal cases. In this series, abdominal injury was uncommon, as were multiple injuries of the spine (fig. 2). Tension pneumothorax or haemo-pneumothorax required urgent treatment; rupture of the diaphragm caused serious circulatory disturbances, and a major chest injury in a patient who also has damage to the cervical spinal cord may

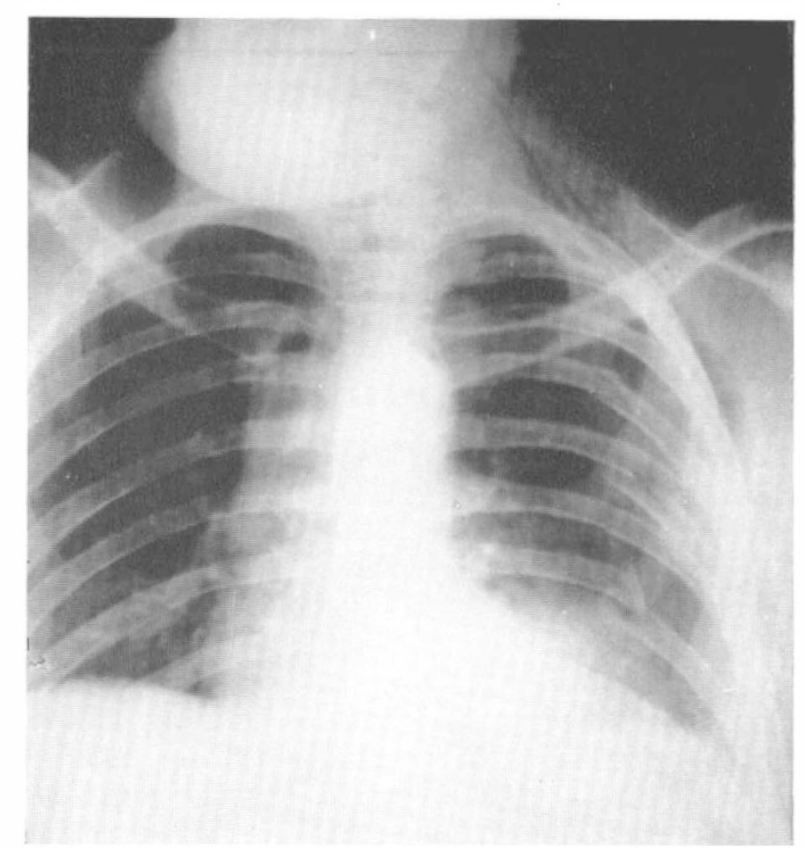

FIG. 3

Radiograph of chest of patient with multiple rib fractures, haemo-pneumothorax and traumatic emphysema.

quickly lead to death unless full therapeutic facilities are available, including intermittent positive pressure respiration (fig. 3). Fifty-four major associated injuries occurred in the 150 patients.

Gissane and Bull (I96I) in their study of I83 deaths from road traffic accidents found evidence of spinal fractures in 20 , with spinal cord injury in four.

\section{MANAGEMENT}

All those associated with the first-aid management, the transportation, and the hospital investigation and treatment of the injured, should be aware of the not uncommon situation of a person sustaining a serious spinal injury and in addition, a significant associated injury. All such personnel require correct instruction, each according to his or her rôle in the management of casualties. Efficient means of transportation must be available, and Gissane (I96I) observes that the prognosis after serious injury is directly related to the time in hours from the accident to the completion of surgery. Proper arrangements are essential for the reception, investigation and treatment of these patients, many of whom 
present difficult and complex medical and nursing problems. They should be admitted as soon as possible to a central accident unit, part of a main general hospital (Harris, pp. I32-I37), where a 24-hour service of consultant and associated staff in the specialties concerned will be available. The first priority is to preserve life, and this includes measures to provide an adequate airway and respiration, to control continuing haemorrhage, treat hypotension, and evacuate any expanding intracranial haematoma. Speed and timing in the management of these patients is vital, and great care must be taken with their handling at all times, as otherwise increasing damage to the spinal neural elements may ensue, and there may also be dangers from obstruction of the airway, and from vomiting and the aspiration of vomitus. The unconscious patient must not be allowed to remain to lie on his back, unless a cuffed intratracheal or tracheostomy tube has been inserted. Associated fracture of a femur or a serious tibial fracture presents special problems for the orthopaedic surgeon in a paraplegic or tetraplegic patient.

\section{SUMMARY}

Associated severe injuries in patients with traumatic paraplegia or tetraplegia are common and in different reported series, including that mentioned in this paper, occur in some 25 per cent. of patients with closed spinal injuries, and up to 65 per cent. with open wounds of the spine.

The diagnosis of the injuries in these patients presents particular difficulties and the important points are detailed, along with commoner sites and the frequency of these injuries. Head injury is the commonest severe associated injury with a cervical cord lesion, and chest injury with a serious injury to the dorsal spine.

Complex clinical problems often ensue, requiring intelligent first aid and rapid transportation to the accident service of a comprehensive hospital, where routine resuscitative measures are applied and investigations and special surgical medical treatments instituted. Priorities of treatment are discussed.

\section{ACKNOWLEDGMENTS}

I have much pleasure in acknowledging the help given to me by $\mathrm{Mr} \mathrm{W}$. E. Strachan, F.R.C.S.E., and Dr D. G. S. Reid, who kindly assisted me in the preparation of this paper.

\section{REFERENCES}

Gissane, W. C. \& Bull, J. P. (I961). Br. med. F. I, I7I6.

Gissane, W. C. (I96I). Lancet, I, 6I2.

Guttmann, L. (1963). Spinal Injuries, p. 8I. Ed. P. Harris. Roy. Coll. Surg. Edin.

Harris, P. (I966). Proc. IIIrd. International Congress of Neurological Surgeons, Copenhagen, Aug. 1965. Excerpta Med. I.C. Series, no. I 10, p. 347.

LiPsCHITZ, R. \& BLOCK, J. (I962). Lancet, 2, I69.

London, P. S. (1964). Clinical Surgery: Accident Surgery, pp. 95-184. Eds. C. Robb and R. Smith. London: Butterworths.

Meirowsky, A. M. (1965). Ed. Neurological Surgery of Trauma. Office of the Surgeon General, Dept. of the Army, Washington.

SCHNEIDER, R. C. \& SCHEMM, G. W. (I96I). F. Neurosurg. I8, 348. 